\title{
The Numerical Analysis of the Effect of Free Convection Heat and Mass Transfer on the Unsteady Boundary Layer Flow Past a Vertical Plate
}

\author{
Abah S.O ${ }^{1, *}$, Eletta B.E ${ }^{2}$, Omale S.O ${ }^{3}$ \\ ${ }^{1}$ Department of Mathematics, Statistics and Computer Science, Kaduna Polytechnic, Kaduna, Nigeria \\ ${ }^{2}$ Department of Applied Science, Kaduna Polytechnic, Kaduna, Nigeria \\ ${ }^{3}$ Department of Chemical Engineering, Kaduna Polytechnic, Kaduna, Nigeria
}

\begin{abstract}
A numerical analysis has been carried out to study the effect of the free convective heat and mass transfer on the unsteady boundary layer flow past a vertical plate. The governing nonlinear partial differential equations have been reduced to systems of nonlinear ordinary differential equations by the similarity transformations. The transformed equations are solved numerically by using sixth order Runge-Kutta the shooting technique. The effects of the Concentration Grashof number $\mathrm{G}_{\mathrm{C}}$, Thermal Grashof number $\mathrm{G}_{\mathrm{T}}$, Prandtl number Pr and Schmidt number Sc are examined on the velocity, temperature and concentration profiles. Numerical data for the skin-friction coefficients, Nusselt and Sherwood numbers have been tabulated for various parametric conditions and are also shown graphically and discussed.
\end{abstract}

Keywords Free Convection, Heat and Mass Transfer, unsteady boundary layer Flow

\section{Introduction}

Free convection flows under the influence of gravitational force have been investigated most extensively because they occur frequently in nature as well as in science and engineering applications. When a heated surface is in contact with the fluid, the result of temperature difference causes buoyancy force, which induces the natural convection. Recently heat flux applications are widely using in industries, engineering and science fields. The problem of boundary layer free convection flow past a semi- infinite vertical plate under different plate conditions was studied by many researchers.

Soundalgekar and Ganesan (1981) investigated the finite difference of transient free convection with mass transfer of an isothermal vertical flat plate. Mahanti and Gaur (2009) presented the effects of varying viscosity and thermal conductivity on steady free convective flow and heat transfer along an isothermal vertical plate in the presence of heat sink. Elbashbeshy and Ibrahim (1993) presented the steady free convection flow with variable viscosity and thermal diffusivity along a vertical plate. Rani (2008) presented the natural convection flow over an isothermal semi-infinite vertical cylinder with effects of variable viscosity and

* Corresponding author:

brosoabah@yahoo.com (Abah S.O)

Published online at http://journal.sapub.org/ijtmp

Copyright (C) 2012 Scientific \& Academic Publishing. All Rights Reserved thermal conductivity. Takhar et al. (1997) analyzed transient free convection past a semi-infinite vertical plate with variable surface temperature. Soundalgekar and Ganesan (1980) studied transient free convective flow past a semi-infinite vertical plate with mass transfer.

The objective of this study is to investigate numerically using similarity transform together with the Runge-Kutta shooting techniques the unsteady heat and mass transfer of a flow over a vertical plate.

\section{Mathematical Analysis of the Problem}

Considering the unsteady free convection and mass transfer flow of a viscous, incompressible fluid past a semi-infinite vertical plate under the influence of the thermal and concentration buoyancy, the flow is assumed to be in the $x$-direction, which is taken along the plate in the upward direction and $y$-axis is normal to it. Initially it is assumed that the plate and the fluid are at the same temperature $T$ and the concentration level everywhere in the fluid is same. At time $\mathrm{t}>0$, the plate temperature and concentration are instantly raised to $T_{w}>T_{\infty}$ and $C_{w}>C_{\infty}$, which are thereafter maintained constant, where $T_{\infty}$ and $C_{\infty}$ are the temperature and concentration respectively outside the boundary layer. Assuming that the Boussinesq and boundary-layer approximations hold, the governing equations to the problem are given by:

$$
\frac{\partial v}{\partial y}=0
$$




$$
\begin{aligned}
\frac{\partial u}{\partial t}=v \frac{\partial^{2} u}{\partial y^{2}}+ & g \beta_{T}\left(T-T_{\infty}\right)+g \beta_{C}(C-C \infty) \\
\frac{\partial T}{\partial t} & =\alpha \frac{\partial^{2} T}{\partial y^{2}} \\
\frac{\partial C}{\partial t} & =A \frac{\partial^{2} C}{\partial y^{2}}
\end{aligned}
$$

With the following the Boundary conditions,

$$
\begin{aligned}
& u=U, T=T_{w}, C=C_{w} \text { at } y=0 \\
& u \rightarrow 0, T \rightarrow T_{\infty}, C \rightarrow C_{\infty} \text { as } \\
& y \rightarrow \infty \text { for } t>0
\end{aligned}
$$

\section{Nomenclature}

$(u, v)=$ Velocity components

$(x, y)=$ Coordinates

$t=$ Time

$T=$ Temperature

$T_{\infty}=$ Free Stream Temperature

$v=$ Kinematic viscosity

$g=$ Gravity

$\beta_{T}=$ Heat transfer Coefficient

$\beta_{C}=$ Mass transfer Coefficient

$C=$ Concentration

$C_{\infty}=$ Free Stream Mass Transfer

$\alpha=$ Thermal Diffusion

$A=$ Coefficient of Mass Diffusion

The mathematical analysis of the problem is simplified by introducing the following dimensionless similarity variables, In order to write the governing equations and the boundary conditions in dimensionless form:

$$
\begin{gathered}
\frac{u}{u_{\infty}}=f(\eta), \text { where } \eta=\frac{y}{2 \sqrt{v t}}, \\
C=\left(C_{w}-C_{\infty}\right) \varphi(\eta)+C_{\infty} \\
T=\left(T_{w}-T_{\infty}\right) \theta(\eta)+T_{\infty}
\end{gathered}
$$

Substituting (6), (7) and (8), the dimensionless quantities, into the governing equations, the transformed Equations (1), (2), (3), and (4) with the transformed boundary conditions are:

$$
\begin{gathered}
f^{\prime \prime}(\eta)+2 \eta f^{\prime}(\eta)+G_{T} \theta(\eta)+G_{C} \varphi(\eta)=0 \\
\theta^{\prime \prime}(\eta)+2 \eta \operatorname{Pr} \theta^{\prime}(\eta)=0 \\
\varphi^{\prime \prime}(\eta)+2 \eta \operatorname{Sc} \varphi^{\prime}(\eta)=0 \\
f(0)=\theta(0)=\varphi(0)=1 \\
f(\infty)=\theta(\infty)=\varphi(\infty)=0
\end{gathered}
$$

Where primes denote differentiation with respect to similarity variable $\eta$ and

$$
\begin{aligned}
& G_{C}=\text { Concentration Grashof number } \\
& G_{T}=\text { Thermal Grashof number } \\
& S c=\frac{v}{A}=\text { Schmindt number } \\
& \operatorname{Pr}=\frac{v}{\alpha}=\text { Plandlt number }
\end{aligned}
$$

\section{Numerical Computation}

The non-linear differential equation (9)-(11) under the boundary conditions (12) and (13) have been solved numerically by deploying a shooting method namely Nachtsheim-Swigert (1995) iteration technique along with sixth order Runge-Kutta iteration scheme. From the process of numerical computation, the skin-friction coefficient, the local Nusselt number and the local Sherwood number, are also sorted out and their numerical values are presented in a tabular form as shown in Table 1.

A representative set of numerical results is shown graphically in Figures 1 to 4 to illustrate the influence of the various physical parameters on the solution.

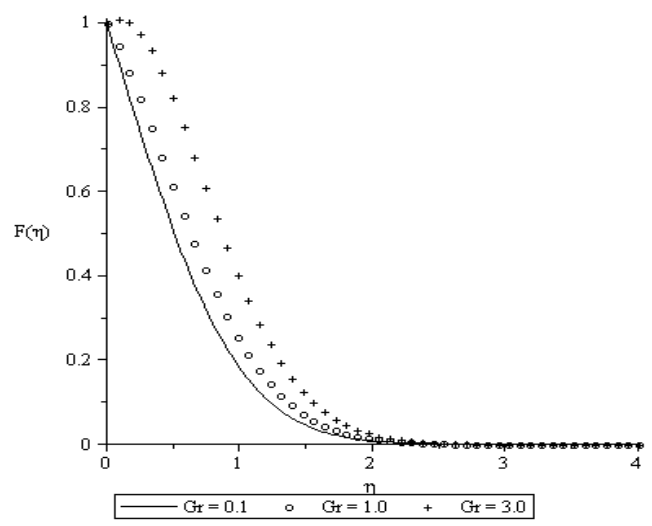

Figure 1. Velocity profiles for various values of $\mathrm{G}_{\mathrm{T}}$ when $\mathrm{G}_{\mathrm{C}}=0.1, \mathrm{Pr}=$ $0.72, \mathrm{Sc}=0.24$

\section{Results and Discussion}

Figure 1 present transient velocity profiles in the boundary layer for various values of Thermal Grashof number $\left(\mathrm{G}_{\mathrm{T}}\right)$. Increasing the value of Thermal Grashof number have the tendency to induce more flow in the boundary layer due to the effect of thermal buoyancy, this buoyancy effects, produces an increase in the velocity flow.

Table 1. Numerical computations showing $f^{\prime}(0), \theta(0)$ and $\varphi(0)$ for various embedded flow parameters.

\begin{tabular}{|c|c|c|c|c|c|c|}
\hline $\mathrm{G}_{\mathrm{T}}$ & $\mathrm{G}_{\mathrm{C}}$ & $\mathrm{Pr}$ & $\mathrm{Sc}$ & $-f^{\prime}(0)$ & $-\theta(0)$ & $-\varphi(0)$ \\
\hline 0.1 & 0.1 & 0.72 & 0.24 & 1.02169613226897349 & 0.957461472963438532 & 0.552790639156493069 \\
\hline 0.5 & 0.1 & 0.72 & 0.24 & 0.84597550538163512 & 0.957461472963438754 & 0.552790639156492069 \\
\hline 1.0 & 0.1 & 0.72 & 0.24 & 0.62632472177246134 & 0.957461472963438088 & 0.552790639156492292 \\
\hline 0.1 & 0.5 & 0.72 & 0.24 & 0.77068461985015368 & 0.957461472963438532 & 0.552790639156492403 \\
\hline 0.1 & 1.0 & 0.72 & 0.24 & 0.45692022932662945 & 0.957461472963438976 & 0.552790639156492958 \\
\hline 0.1 & 0.1 & 3.00 & 0.24 & 1.03991355214434478 & 1.954410047611680582 & 0.552790639156492736 \\
\hline 0.1 & 0.1 & 7.10 & 0.24 & 1.04764742728992900 & 3.006659403328317833 & 0.552790639156492292 \\
\hline 0.1 & 0.1 & 0.72 & 0.62 & 1.03819785463574332 & 0.957461472963439086 & 0.888486644658095570 \\
\hline 0.1 & 0.1 & 0.72 & 2.62 & 1.05730762800839484 & 0.957461472963438310 & 1.826441241104166612 \\
\hline
\end{tabular}




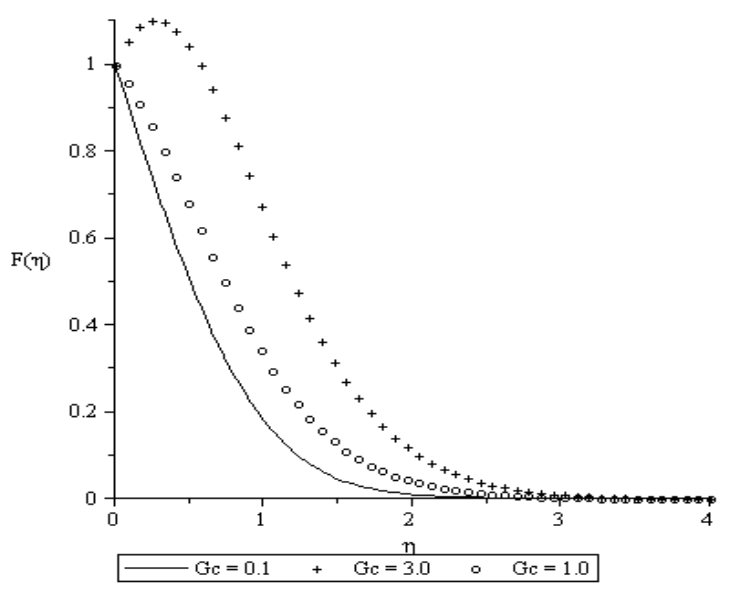

Figure 2. Velocity profiles for various values of $\mathrm{G}_{\mathrm{C}}$ when $\mathrm{G}_{\mathrm{T}}=0.1, \mathrm{Pr}=$ $0.72, \mathrm{Sc}=0.24$

The Velocity profiles for various values of Concentration Grashof number $\left(\mathrm{G}_{\mathrm{C}}\right)$ when $\mathrm{G}_{\mathrm{T}}=0.1, \mathrm{Pr}=0.72$ and $\mathrm{Sc}=0.24$ is depicted in figure 2. It is clearly seen that the velocity increases with the increase of the Concentration Grashof number.

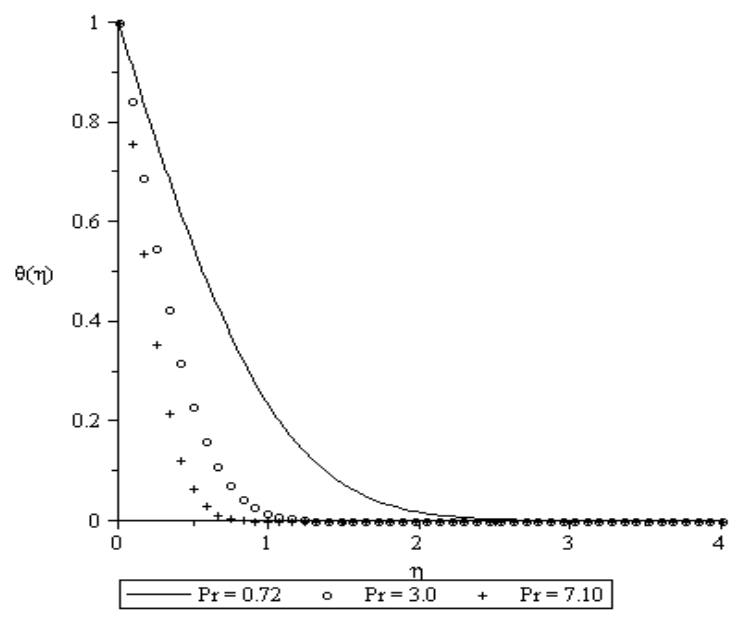

Figure 3. Temperature profiles for various values of Prandtl number When $\mathrm{G}_{\mathrm{T}}=\mathrm{G}_{\mathrm{C}}=0.1, \mathrm{Sc}=0.24$

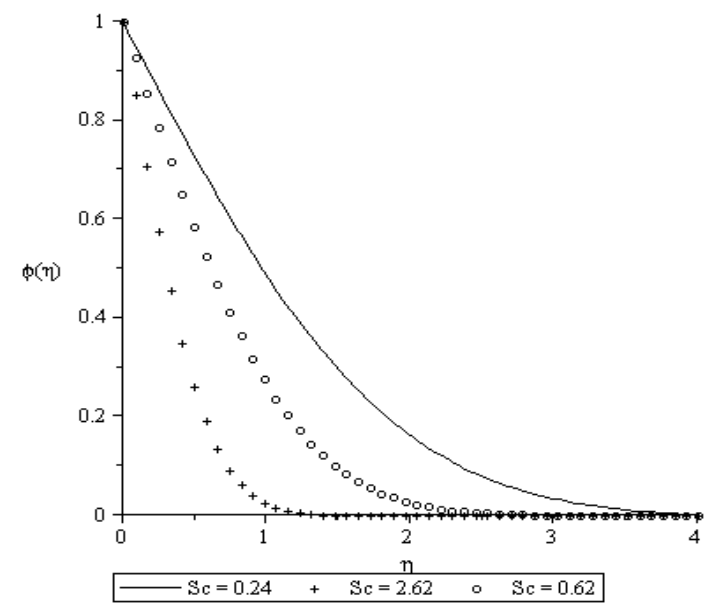

Figure 4. Concentration profiles for various values of Schmidt number Sc when $\mathrm{G}_{\mathrm{T}}=\mathrm{G}_{\mathrm{C}}=0.1, \operatorname{Pr}=0.72$
The effect of Prandtl number (Pr) on the temperature profiles is shown in Figure 3. It is observed that an increase in the Prandtl number results in a decrease of the thermal boundary layer thickness and in general lower average temperature within the boundary layer. The reason is that smaller values of Prandtl number are equivalent to increase in the thermal conductivity of the fluid and therefore heat is able to diffuse away from the heated surface more rapidly for higher values of Prandtl number. Hence there is a reduction in temperature with increase in the Prandtl number.

Figure 4 illustrate the influence of the Schmidt number (Sc) on the concentration. It indicates the concentration profiles showing the effect of Schmidt number. It can be seen that concentration profiles decrease very rapidly and the hydrodynamic, thermal and concentration boundary layer thickness reduce with the increase of Schmidt number. Hence, as Schmidt number increases the concentration decreases.

\section{Conclusions}

A theoretical study of the characteristics unsteady boundary layer flow over a vertical plate has been carried out. The nonlinear boundary layer equations governing the problem under consideration are solved numerically by applying an efficient numerical technique based on RungeKutta of order six as well as the shooting method. Numerical solution shows the influence of the various physical parameters on the velocity, temperature and concentration profile were performed.

The present analysis has shown that;

An increase in the thermal Grasshof and the Concentration Grashof number leads to increase in the velocity profile.

And that, rise in the Prandtl number leads to a decrease in the temperature profile.

And also a rise in the Schmidt number produces a decrease in the concentration profile.

\section{REFERENCES}

[1] B.Vasu, V. Ramachandra Prasad and N. Bhaskar Reddy, Radiation and Mass Transfer Effects on Transient Free Convection Flow of a Dissipative Fluid Past Semi-Infinite Vertical Plate with Uniform Heat and Mass Flux. JAFM, Vol.4(1),7,15-26.

[2] P. Loganathan et. al. / International Journal of Engineering Science and Technology Vol. 2(11), 2010, 6257-6268.

[3] V.M. Soundalgekar, P. Ganesan., (1981). The finite difference analysis of transient free convection with mass transfer of an isothermal vertical flat plate, Int. J. Engg Sci. 19, pp.757-770.

[4] N.C.Mahanti, P. Gaur.,(2009) The effects of varying viscosity and thermal conductivity on steady free convective flow and heat transfer along an isothermal vertical plate in the presence of heat sink. Journal of Applied Fluid Mechanics, 2(1), pp.23-28. 
[5] Elbashbeshy and Ibrahim.,(1993). Steady free convection flow with variable viscosity and thermal diffusivity along a vertical plate. Journal of Physics: Applied Physics, 26(12).

[6] Havstad MA and Burns PJ(1982): Int. J. Heat \&Mass Transfer, V.25,No.1, p.1755.

[7] H. Schlichting,(1979)Boundary Layer Theory, McGraw-Hill, New York.

[8] E. R. G. Eckert and Robert M. Drake.,(1963). Heat and Mass transfer, McGraw-Hill, New York.
[9] H.P. Rani and Chang Nyung Kim.,(2008). Transient convection on vertical cylinder with variable viscosity and thermal conductivity. Journal of Thermo physics and Heat Transfer, 22 (2), pp. 254-261.

[10] H. S. Takhar, P. Ganesan, K. Ekambavanan and V. M. Soundalgekar.,(1997). Transient free convection past a semiinfinite vertical plate with variable surface temperature, Int.J. Numer. Methods Heat Fluid Flow, 7 , pp.280 - 296.

[11] Soundalgekar, V.M. and Ganesan, P., (1980). Transient free convective flow past a semi-infinite vertical plate with mass transfer, Reg. J. Energy Heat and Mass Transfer,2, No.1,83. 